\title{
Scoping review of risk factors of and interventions for adolescent repeat pregnancies: A public health perspective
}

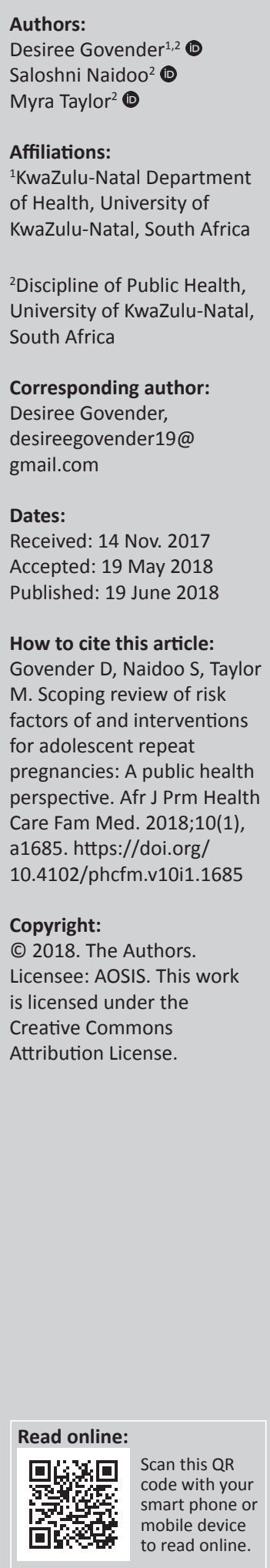

Background: Adolescent repeat pregnancy is of importance in public health because the birth of a second child to an adolescent mother compounds the adverse medical, educational, socioeconomic and parenting outcomes. Repeat pregnancy in adolescence is not only an international phenomenon but also a local concern as it also occurs in South Africa. The prevalence of adolescent repeat pregnancy in Durban, KwaZulu-Natal, was reported as 17.6\% in 2013.

Aim: This review aimed to gather relevant information from national and international sources to inform practice and to provide an understanding of what is known about the risk factors of and the interventions for adolescent repeat pregnancy.

Methods: A scoping review was undertaken using the Arksey and O'Malley framework. An electronic search was conducted using PubMed, Medline, Science Direct, Ebscohost, Sage and Wiley Online and Google Scholar.

Results: The search identified 3032 citations. After a review of the full text articles, 26 articles met the inclusion criteria. Risk factors pertaining to adolescent repeat pregnancy are categorised according to individual factors, partner relationship factors, family factors, peer factors, and social and community factors. Interventions to reduce adolescent repeat pregnancy have been largely influenced by the ecological framework. Across studies, adolescent mothers who received medical, psychosocial, educational, and family planning support experienced lower rates of repeat pregnancy.

Conclusion: A single 'one-size-fits-all' intervention for adolescent repeat pregnancy prevention is unlikely as different strategies were employed by the intervention programmes in this scoping review.

\section{Introduction}

Adolescent childbearing and repeat pregnancy are both public health and social problems. ${ }^{1}$ Darroch et al. ${ }^{2}$ reported that worldwide approximately 21 million girls in the 15-19 years age category became pregnant in 2016. ${ }^{2}$ Furthermore, adolescent pregnancy and childbirth complications are a leading cause of the global burden of poor maternal health conditions and death in the $15-19$ years age category. ${ }^{3}$ The prevalence of adolescent repeat pregnancy is alarming. Approximately $12 \%-49 \%$ of adolescent repeat pregnancies in the United States of America (USA) occur within 1 year of the previous pregnancy. ${ }^{4}$ Supporting data from Australia and Canada indicate that the prevalence of adolescent repeat pregnancy in these countries is $33 \%$ and $15.2 \%$, respectively. ${ }^{5,6}$ In the United Kingdom, one-fifth of births to adolescents under 18 years of age are repeat pregnancies. ${ }^{7}$ Repeat pregnancy amongst adolescents is not only an international phenomenon, but it also occurs in South Africa. Though the national prevalence of adolescent repeat pregnancy is not known in South Africa, the prevalence in Durban, KwaZulu-Natal was reported to be $17.6 \%$ in $2013 .{ }^{8}$

Adolescent repeat pregnancy is of particular importance in public health because the birth of a second child to an adolescent mother compounds the adverse medical, educational, socioeconomic and parenting outcomes. ${ }^{9,10}$ In addition, girls who have repeat adolescent pregnancies generally experience suicidal ideation, depression and anxiety. ${ }^{11}$ Adolescent parenting stress also increases with rapid repeat pregnancy, which could result in neglect of the second child and negative parenting behaviour. ${ }^{12}$ Adolescent parents bearing two or more children within a period of 5 years are more likely to rely on social grants, drop out of school and experience additional childbearing within shorter birth intervals. ${ }^{4,10,13,}$ In the USA, taxpayers contribute almost $\$ 7$ billion 
towards the burden of adolescent childbearing which includes health care, criminal justice, foster care, and public social and economic assistance. ${ }^{13}$

Researchers have often referred to the topic of adolescent childbearing and rapid repeat pregnancy as a phenomenon or an enigma. ${ }^{7,12,14}$ A range of opinions have been forwarded amongst public health professionals, clinicians, social scientists, advocacy groups and the media regarding the issue of adolescent pregnancy. The current debate centres on the conceptualisation of adolescent pregnancy as a public health problem versus adolescent pregnancy as a reproductive choice and process. Adolescent pregnancy is culturally accepted in different parts of the world despite being labelled a public health problem. Some adolescent health experts have refuted the claim that adolescent pregnancy results in catastrophe for the mother and her infant. ${ }^{15,16}$ Macleod $^{15}$ argues that the moral judgment of adolescent pregnancy has now been substituted by 'scientific scrutiny' (p. 59).

A study by Smith and Pell ${ }^{17}$ found a causal association between repeat adolescent pregnancy and poor birth outcomes. However, these findings were dismissed on the stance that adolescent repeat pregnancy is not a public health problem and that birth outcomes are largely influenced by confounders such as socio-economic circumstances. ${ }^{18}$ Criticising Lawlor and Shaw's ${ }^{18}$ argument that adolescent pregnancy is not a public health problem, Scally ${ }^{19}$ argues that adolescent pregnancy requires integrated public health action through several sectors to help adolescents prevent unwanted pregnancies and manage the health, economic and social consequences of the pregnancy and birth. In support of Scally's $\mathrm{s}^{19}$ assertions, Rich-Edwards ${ }^{20}$ advances the explanation that poverty is a risk factor for adolescent pregnancy and that premature parenthood influences the cycle of future poverty, making this a public health problem.

On the basis of these arguments, the literature review was essential in facilitating a better understanding of the public health approach towards adolescent repeat pregnancy. Understanding the risk factors of and the interventions for adolescent repeat pregnancy can provide guidance to health practitioners and decision makers. This scoping review was designed with the purpose of gathering relevant information from national and international sources to inform practice and to provide an understanding of what is known about the risk factors of and the interventions for adolescent repeat pregnancy.

\section{Defining repeat adolescent pregnancy}

The literature distinguishes between adolescent repeat pregnancy and rapid adolescent repeat pregnancy. Adolescent repeat pregnancy is defined as a second pregnancy or additional pregnancies to a woman younger than 20 years of age. ${ }^{6}$ Most research to date has focused on rapid repeat pregnancy amongst adolescents. ${ }^{21,22,23,24,25,26}$ Rapid adolescent repeat pregnancy is defined as a second birth or pregnancy that occurs within 2 years of the previous pregnancy. ${ }^{24}$

\section{Methods}

This literature review employed a scoping review methodology based on the framework by Arksey and $\mathrm{O}^{\prime} \mathrm{Malley}^{27}$ and the recommendations put forward by Levac et al. ${ }^{28}$ According to Davies et al., ${ }^{29}$ '... scoping involves the synthesis and analysis of a wide range of research and non-research material to provide greater conceptual clarity about a specific topic or field of evidence' (p. 1386). The study followed the stages of the Arksey and $\mathrm{O}^{\prime}$ Malley ${ }^{27}$ framework which included: (1) identifying the research question, (2) identifying relevant studies, (3) study selection, (4) charting the data and (5) collating, summarising and reporting the results.

\section{The research question}

The research question was generated by our public health concerns about adolescent repeat pregnancy. The scoping review was guided by the research question: 'what are the risk factors of, and the interventions for adolescent repeat pregnancy?' A key aspect of a scoping review is a broad and comprehensive research question to provide breadth of the literature.

\section{The data sources and search strategy}

The databases used to conduct the literature search were selected on the basis that the topic of adolescent repeat pregnancy encompasses social science research and public health research. The databases included PubMed, Medline, Science Direct, Ebscohost and Wiley Online. Search engines included Google and Google Scholar. The search terms included 'adolescent pregnancy' and/or 'adolescent repeat pregnancy' and/or 'adolescent parenting' and/or 'adolescent repeat pregnancy risk factors' and/or 'consequences of adolescent pregnancy' and/or 'secondary pregnancy prevention'. The snowballing technique was applied by identifying references in the scrutinised review articles to obtain detailed and relevant information. Searching involved published literature from 1990 to 2016.

\section{Study selection}

When the relevant literature was identified, the inclusion and exclusion criteria were established (Table 1). The papers that were included for this scoping study comprised published peer review studies, review articles and opinion articles. Figure 1; depicts the scoping process which includes the number of publications retrieved and selected from the database search.

\section{Charting the data}

An electronic data spreadsheet was developed. Data were extracted according to the following details: author information, title, journal, year of publication, identified risk 
TABLE 1: Inclusion and exclusion criteria.

\begin{tabular}{|c|c|}
\hline Inclusion & Exclusion \\
\hline - Articles written in English. & - Articles not written in English. \\
\hline $\begin{array}{l}\text { - Articles involving a secondary or repeat } \\
\text { pregnancy prevention intervention for } \\
\text { adolescents. }\end{array}$ & $\begin{array}{l}\text { - Articles focusing on primary } \\
\text { pregnancy prevention for } \\
\text { adolescents. }\end{array}$ \\
\hline $\begin{array}{l}\text { - Study participants were defined as } \\
\text { adolescents ( } 13 \text { to } 19 \text { years of age). }\end{array}$ & $\begin{array}{l}\text { - Study participants who were not } \\
\text { defined as adolescents. }\end{array}$ \\
\hline $\begin{array}{l}\text { - Articles identifying risk factors of repeat } \\
\text { adolescent pregnancy. }\end{array}$ & - Articles published before 1990. \\
\hline $\begin{array}{l}\text { - Intervention studies with baseline and } \\
\text { post-intervention data. }\end{array}$ & \\
\hline $\begin{array}{l}\text { - The outcome of interest had to include } \\
\text { reduced adolescent repeat pregnancy rate. }\end{array}$ & \\
\hline
\end{tabular}

\begin{tabular}{|c|c|}
\hline \multicolumn{2}{|c|}{ IDENTIFICATION } \\
\hline $\begin{array}{l}3032 \text { records identified through data } \\
\text { base search }\end{array}$ & 334 duplicates excluded \\
\hline \multicolumn{2}{|c|}{ SCREENING } \\
\hline $\begin{array}{l}2698 \text { records entered into title and } \\
\text { abstract review }\end{array}$ & 2611 records excluded \\
\hline \multicolumn{2}{|c|}{ ELIGIBILITY } \\
\hline $\begin{array}{l}87 \text { full text articles included for } \\
\text { eligibility }\end{array}$ & $\begin{array}{l}61 \text { articles excluded for not meeting } \\
\text { inclusion criteria }\end{array}$ \\
\hline \multicolumn{2}{|c|}{ INCLUDED } \\
\hline $\begin{array}{r}26 \text { articles included for final analysis } \\
\text { repeat pregnancy and } 17 \text { articles } \\
\text { pregnancy }\end{array}$ & $\begin{array}{l}\text { articles on risk factors of adolescent } \\
n \text { articles on adoloescent repeat } \\
\text { evention. }\end{array}$ \\
\hline
\end{tabular}

FIGURE 1: Article selection process.

factors, study design, study setting, participants, intervention and the related health outcome.

\section{Ethical Considerations}

This literature review was part of a larger doctoral study that had been approved by the University of KwaZuluNatal Bioethics Research Committee (ref no: BFC553/16) and the KwaZulu-Natal Department of Health (ref no. KZ_2016RP26_545).

\section{Results \\ Description of studies}

The online searches yielded 3032 relevant citations of which 2698 were eligible for title and abstract review. Of these, a total of 87 articles were retrieved for full text screening. After review of the full text articles, 26 articles met the inclusion criteria (illustrated in Figure 1). The articles were summarised into themes of risk factors and of interventions for adolescent repeat pregnancy. Nine of the 26 articles addressed the risk factors of adolescent repeat pregnancy. The majority of the studies (67\%) addressing the risk factors of adolescent repeat pregnancy were from the USA. The description of included studies for the risk factors of adolescent repeat pregnancy is presented in Table 2. Seventeen articles in this scoping review addressed interventions on adolescent repeat pregnancy. Details of these 17 articles included for the analysis and discussion of the interventions on adolescent repeat pregnancy are presented in Table 3.

Rowland ${ }^{30}$ demonstrates a comprehensive ecological model for the predictors of rapid repeat pregnancy amongst adolescent mothers. For adolescents experiencing a repeat pregnancy, the risk factors are categorised according to individual factors, partner relationship factors, family factors, peer and school factors and social and community factors (Table 4).

The individual factors relating to adolescent repeat pregnancy include race, ethnicity, age of first pregnancy, int. ended first pregnancy and attitudes towards early childbearing ${ }^{10,30,31}$ In addition, cognitive functioning and a history of depression have been linked to adolescent repeat pregnancies. ${ }^{14}$ Lewis et al. ${ }^{22}$ found that repeat pregnancy was more likely in indigenous Australian adolescents (odds ratio 2.38, 95\% confidence interval (CI) 1.38-4.11). Poor obstetrical outcomes such as miscarriages have been associated with rapid repeat adolescent pregnancy. Partner relationship factors such as living with an older partner, being married at a young age, having a new partner and intimate partner violence are more common in those adolescents with a repeat pregnancy. ${ }^{30,31}$ Family factors that are related to subsequent adolescent repeat pregnancies include dysfunctional mother-daughter relationships, having mothers with low educational levels, intergenerational adolescent pregnancy, and lack of family support..$^{30,31}$

Equally important, an adolescent mother who lives with her mother after the birth of her first child and relies on her mother for financial and social support is more likely to experience a repeat adolescent pregnancy. ${ }^{30,31}$ Peer factors in particular, such as association with friends who are adolescent parents, postpartum school enrolment and low educational ambition, have been linked with adolescent repeat pregnancy. ${ }^{30,32}$ The social and community factors associated with adolescent repeat pregnancy include low socio-economic status, low educational status, and society norms that accept adolescent childbearing. ${ }^{30,31,32}$

These ecological factors have been tested in studies conducted by Lewis et al., ${ }^{22}$ Jacoby et al., ${ }^{23}$ and Raneri and Wiemann. ${ }^{24}$ Jacoby et al. ${ }^{23}$ found a strong association between adolescent rapid repeat pregnancy and interpersonal violence $\left(p<0.00001\right.$; odds ratio 22.6). Similarly, Raneri and Wiemann ${ }^{24}$ demonstrated that adolescents with repeat pregnancies had been physically abused by their boyfriends or husbands 
TABLE 2: Description of included studies for risk factors of adolescent repeat pregnancy.

\begin{tabular}{|c|c|c|c|c|}
\hline Author (year) & Country & Title & Study design & Number of participants \\
\hline Boardman et al. (2006) & USA & $\begin{array}{l}\text { Risk factors for unintended versus intended rapid repeat pregnancies } \\
\text { amongst adolescents. }\end{array}$ & $\begin{array}{l}\text { Retrospective observational } \\
\text { cohort }\end{array}$ & 1117 \\
\hline Crittenden et al. (2009) & USA & $\begin{array}{l}\text { The role of mental health factors, behavioral factors and past experiences } \\
\text { in the prediction of rapid repeat pregnancy in adolescents. }\end{array}$ & Retrospective cohort study & 357 \\
\hline Jacoby et al. (1999) & USA & $\begin{array}{l}\text { Rapid repeat pregnancy and experiences of interpersonal violence } \\
\text { amongst low-income individuals. }\end{array}$ & $\begin{array}{l}\text { Case control study using } \\
\text { retrospective chart review }\end{array}$ & 100 \\
\hline Lewis et al. (2010) & Australia & $\begin{array}{l}\text { Predictors of sexual intercourse and rapid repeat pregnancy amongst } \\
\text { teenage mothers: An Australian prospective longitudinal study. }\end{array}$ & $\begin{array}{l}\text { Prospective longitudinal } \\
\text { study }\end{array}$ & 147 \\
\hline Mphatswe et al. (2016) & South Africa & $\begin{array}{l}\text { Prevalence of repeat pregnancies and associated factors amongst teenage } \\
\text { mothers in KwaZulu-Natal. }\end{array}$ & $\begin{array}{l}\text { Prospective observational } \\
\text { study }\end{array}$ & 341 \\
\hline Pfitzner et al. (2003) & USA & Predictors of repeat pregnancy in program for pregnant teens. & $\begin{array}{l}\text { Retrospective case control } \\
\text { study }\end{array}$ & 1838 \\
\hline Raneri and Wiemann (2007) & USA & Social ecological predictors of adolescent repeat pregnancy. & Retrospective cohort study & 932 \\
\hline Rowland (2010) & UK & Social predictors of repeat adolescent pregnancy and focused strategies. & Literature review & N/A \\
\hline Rigsby et al. (1998) & USA & $\begin{array}{l}\text { Risk factors for rapid repeat pregnancy amongst adolescent mothers: } \\
\text { A review of the literature. }\end{array}$ & Systematic review & $\begin{array}{l}\text { Included } 20 \text { studies for } \\
\text { analysis }\end{array}$ \\
\hline
\end{tabular}

Note: Please see the full reference list of the article, Govender D, Naidoo S, Taylor M. Scoping review of risk factors of and interventions for adolescent repeat pregnancy: A public health perspective. Afr J Prm Health Care Fam Med. 2018;10(1), a1685. https://doi.org/10.4102/phcfm.v10i1.1685, for more information.

USA, United states; UK, United Kingdom; N/A, not applicable.

within the first 3 months of the delivery (odds ratio 1.85, 95\% CI: 1.18-2.88). Lewis et al..$^{22}$ acknowledged that the following factors increased the risk of adolescent repeat pregnancy amongst Australian adolescent mothers: (1) living with the father of the child $(p<0.001)$, (2) recommencement of sexual intercourse before 6 weeks postpartum $(p<0.005)$, (3) oral contraceptive use $(p<0.005)$ and $(4)$ ongoing sexual intercourse $>3$ months $(p<0.005)$.

Raneri and Wiemann et al. ${ }^{24}$ also recognised that the risk of adolescent repeat pregnancy correlated positively with the following: (1) plans to have a baby in $\leq 5$ years (odds ratio $1.55,1.03-2.34),(2)$ not using a long-acting contraceptive within 3 months after delivery (odds ratio 2.38, 95\% CI: 1.61-3.52), (3) not in a relationship with the father of the first child 3 months after delivery (odds ratio 2.04, 95\% CI: 1.37-3.05), (4) father of first child $>3$ years older (odds ratio 1.60, 95\% CI: 1.10-2.35), (5) not enrolled in school 3 months after delivery (odds ratio 1.75, 95\% CI: 1.20-2.55) and (6) $\geq$ half of friends were adolescent mothers at delivery (odds ratio $1.52,95 \% \mathrm{CI}: 1.03-2.26)$.

In the South African context, Mphatswe et al. ${ }^{8}$ found that adolescents with repeat pregnancies were involved with partners who were 5 years or older than them, or they had had multiple sexual partners in the previous 12 months. The prevalence of HIV was also higher in South African adolescent repeat pregnancies than in first time adolescent pregnancies.

According to Raneri and Wiemann ${ }^{24}$ the strongest predictor of adolescent repeat pregnancy is not using a long-acting contraceptive postpartum. Steven-Simons et al. ${ }^{26}$ investigated the adoption of the contraceptive implant to avoid adolescent repeat pregnancy. The authors found that the rate of repeat adolescent pregnancy was significantly lower for early implant users $(12 \%, p<0.0001)$ than for other adolescent mothers using alternative methods of contraception (46\%). Lewis et al..$^{22}$ demonstrated that this claim was warranted and advocated for the provision of long-acting contraceptives to adolescent mothers.

\section{Interventions to prevent adolescent repeat pregnancy}

Interventions to reduce adolescent repeat pregnancy have been largely influenced by the ecological framework of individual, partner, familial, peer, and community factors (Table 5). First time adolescent mothers who attended the Queens Hospital community-based programme in the USA, which provided medical, psychosocial, educational and family planning support through a multidisciplinary team (i.e. a team including a gynaecologist, paediatrician, social worker and health educator), had a lower repeat pregnancy rate $(9 \%)$ than the control group $(70 \%){ }^{33}$

Similarly, O'Sullivan and Jacobsen ${ }^{34}$ found that only $12 \%$ of the adolescent mothers who participated in the health care programme for first time adolescent mothers (behavioural skills development, contraceptive education, life option enhancement, sexuality, HIV and sexually transmitted infections (STI) education, infant care and education support attainment) had a repeat pregnancy in comparison to $28 \%$ of adolescent mothers in the control group at 18 months postpartum.

A study carried out by Cox et al. ${ }^{21}$ in the USA also evaluated a hospital community-based medical home model for adolescent mothers and their children in which the outcomes of programme retention, health care utilisation, infant immunisation status, contraceptive use, repeat pregnancy, depressive symptoms, social support, school attendance and employment status were measured. The study design was a prospective single cohort study with the following programme components; infant care education, life orientation, social services support, family support groups, contraceptive education, day care and community outreach services. As there was no control group, benchmark comparison data were used through a systematic literature review. The adolescent repeat pregnancy rate was $14.7 \%$ at 12 months and $24.6 \%$ at 24 months. Cox et al. ${ }^{21}$ compared the findings of their study to those of Barnet et al., ${ }^{9}$ who found that the repeat pregnancy rate amongst adolescent mothers in the intervention group was $45 \%$ at 24 months. 

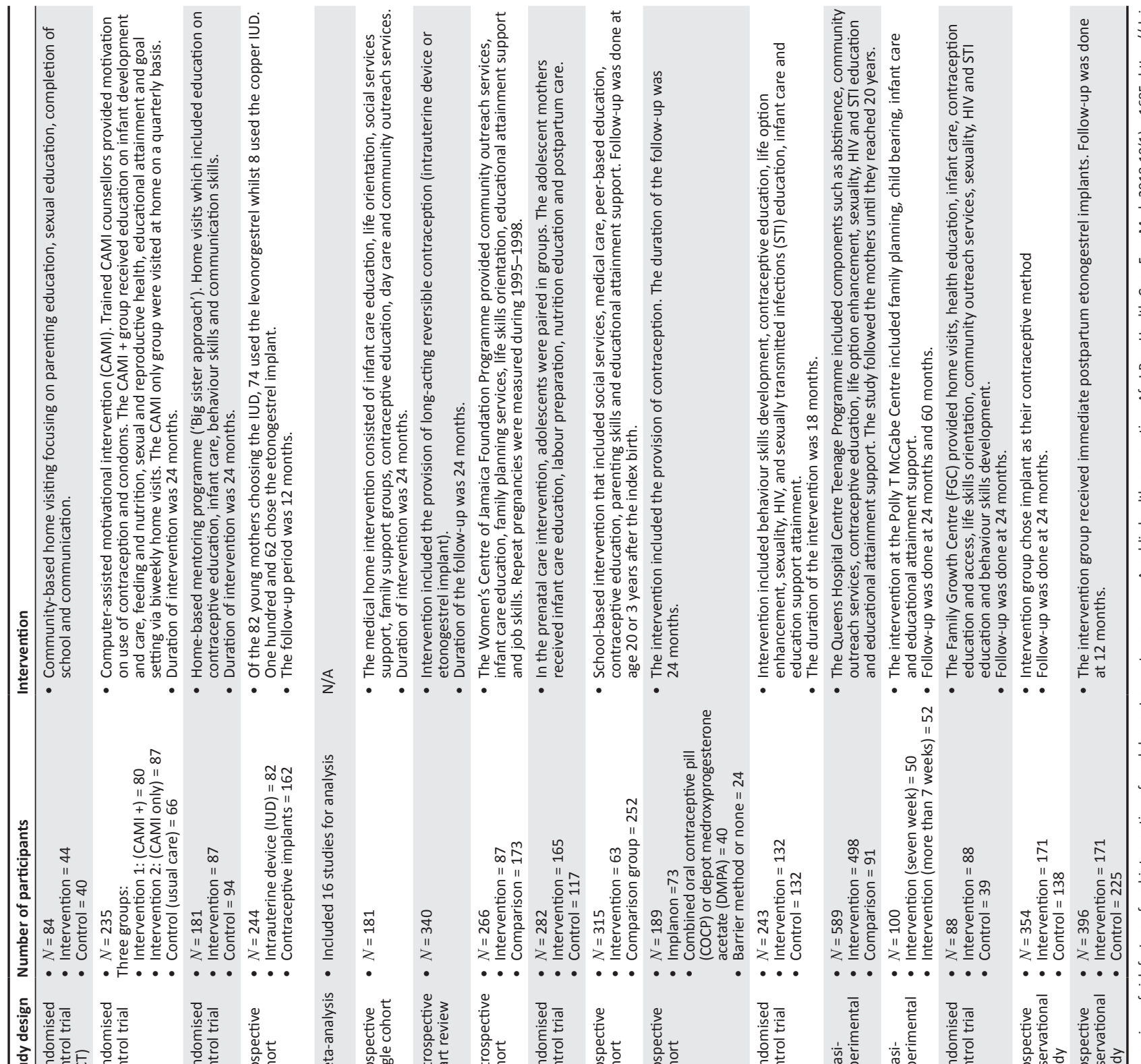

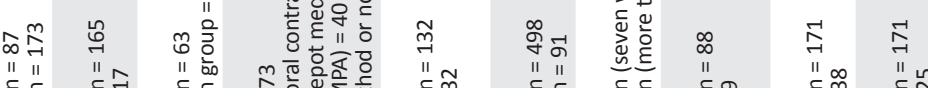

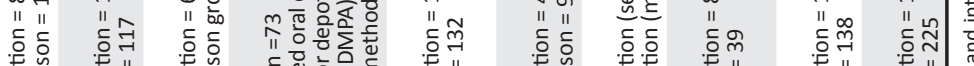

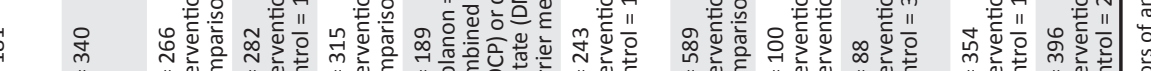

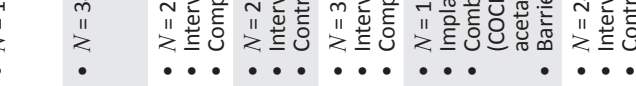

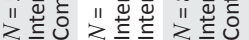

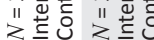

\section{Un}

Intent

11

$\sqrt{1}$

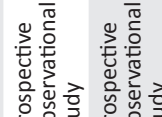

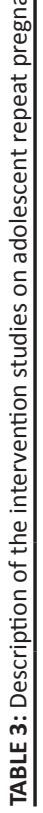

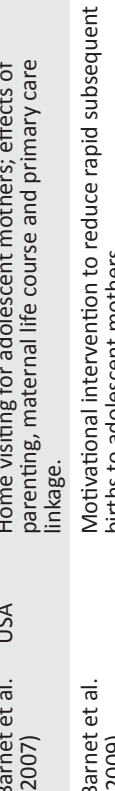

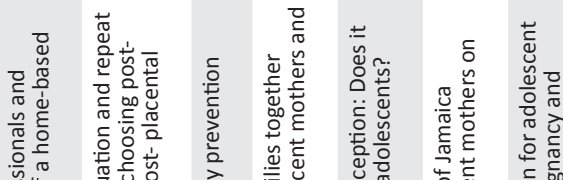

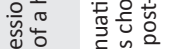

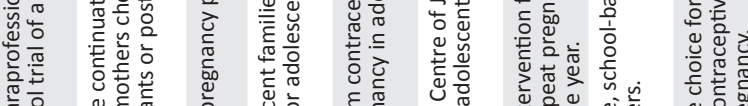

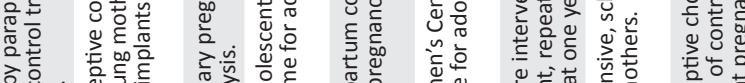

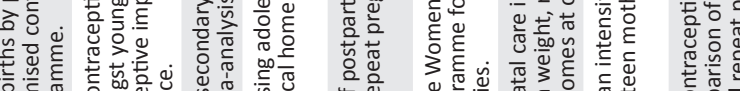

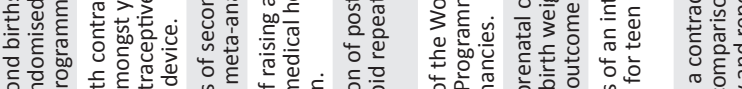

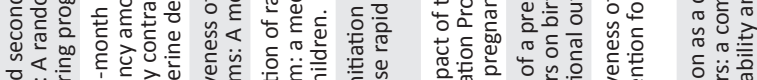
MInIn ym Hn num I
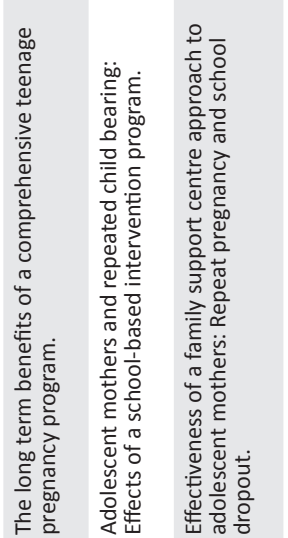

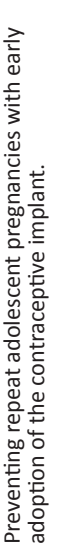
政

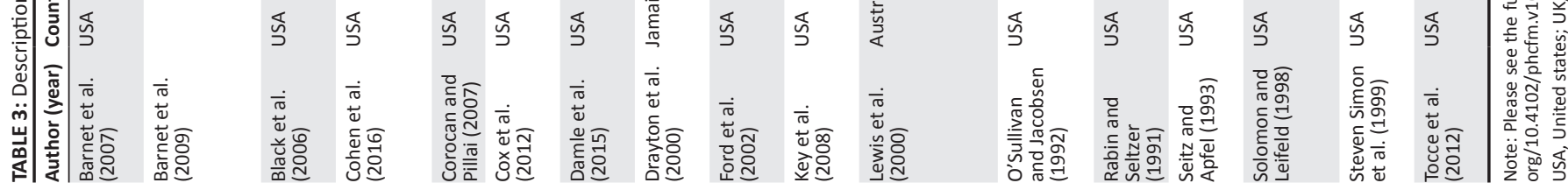


Numerous studies have focused on specific community-based health care centres for adolescent mothers with emphasis on secondary pregnancy prevention. For example, Solomon and Liefeld ${ }^{25}$ reported on the success of a family growth centre (FGC) where the repeat pregnancy rate amongst adolescent mothers in the intervention group was $12 \%$ in comparison to $41 \%$ in the control group in a 3-year longitudinal study. The FGC was designed using the Ecological Model and the Family Support Model, taking into consideration that adolescent pregnancy does not occur in a vacuum. Similarly, the Women's Centre of Jamaica Foundation (WCJF) Programme for adolescent mothers found that the programme participants' risk of a repeat pregnancy was reduced by $45 \% 4$ years post evaluation. ${ }^{35}$ The WCJF programme components included community-based pregnancy prevention, parenting education, family planning services, life skills orientation, job training and placement, counselling services for adolescent fathers, and school support services.

By employing the ecological framework and social cognitive theory (SCT), Ford et al. ${ }^{36}$ evaluated a peer-centred prenatal programme for adolescent mothers. The study focused on birth weight, repeat pregnancy and educational outcomes at 12 months postpartum. The intervention included group therapy and prenatal education whilst the control group received the usual individual prenatal care. Whilst it can be argued that the repeat pregnancy differences between the intervention and control groups were not statistically significant, the repeat pregnancy rate in the peer-centred prenatal programme was lower than in the control group (13.4\% vs. $15.9 \%)$

Some authors argue that school-based programmes for adolescent mothers are also effective in reducing repeat pregnancies. ${ }^{37,38}$ For example, in a South Carolina high school, a school-based programme that provided comprehensive care found that the repeat pregnancy rate was $17 \%$ in the treatment group in comparison to $29 \%$ in the control group at 3 years after the previous birth. ${ }^{37}$ The school-based programme included medical services, social services, peerbased education, contraceptive education, parenting skills and educational attainment support for adolescent mothers. In a similar school-based programme, at the Polly T McCabe Centre, adolescent mothers who stayed for more than 7 weeks at the school-based centre had a lower repeat pregnancy rate at 24 months versus the adolescent mothers who stayed at the centre for 7 weeks only $(12 \%, 6 / 50$ vs. $36 \%$, $19 / 52, p=0.005) .^{38}$ In addition, Corocan and Pillai's $\mathrm{s}^{39}$ meta-analysis of 16 studies focusing on adolescent repeat pregnancy prevention programs, which included schoolbased programs, revealed a 50\% reduction in the likelihood of repeat pregnancies.

Apart from community and school-based interventions, home nurse visiting and motivational interviewing (MI) have also proven to be effective in delaying and reducing repeat pregnancies amongst adolescent mothers. ${ }^{37,40,41}$ The effects of a home-based mentoring programme on repeat pregnancy prevention for first time adolescent mothers was evaluated 
TABLE 5: Intervention outcomes.

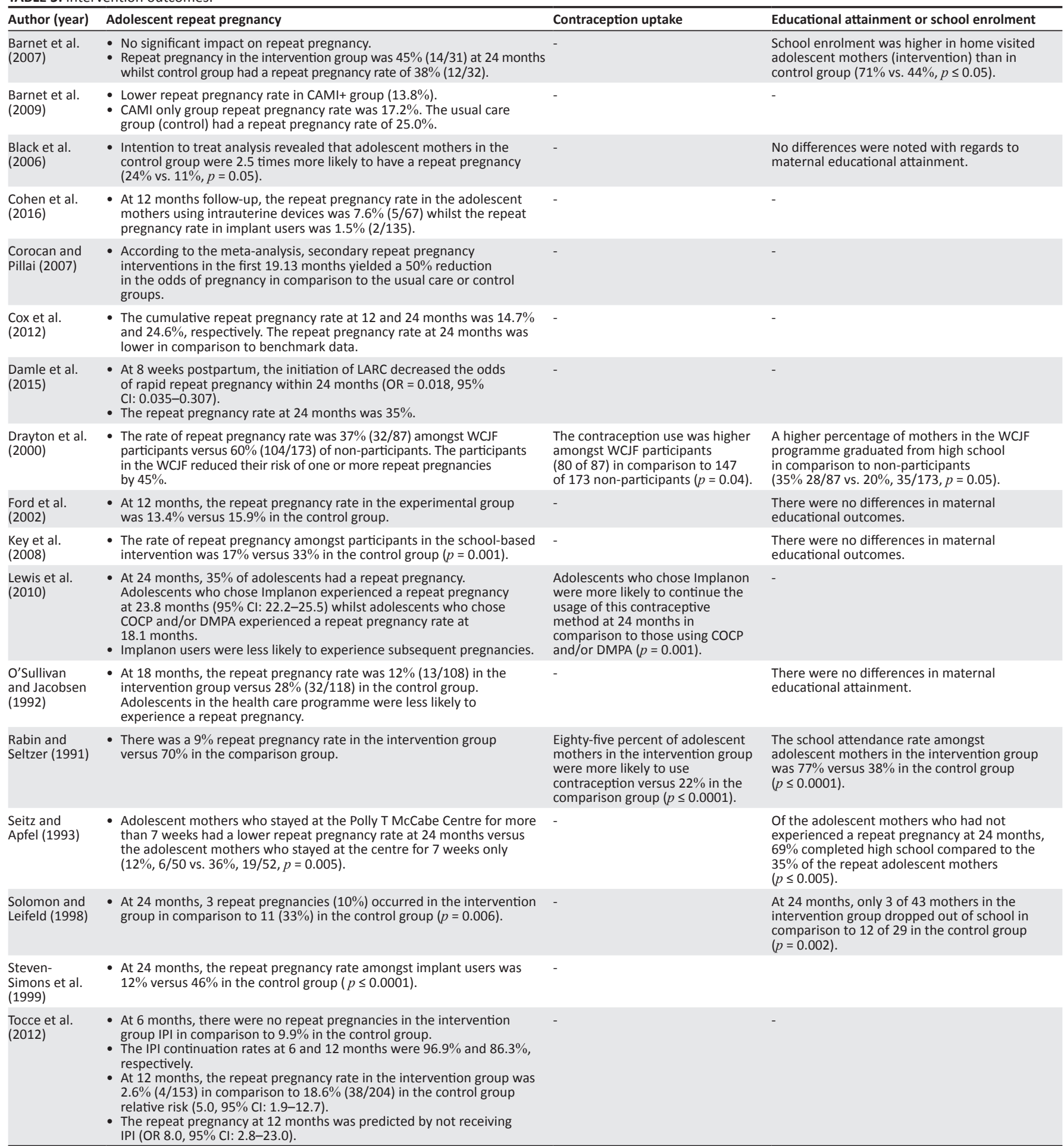

Note: Please see the full reference list of the article, Govender D, Naidoo S, Taylor M. Scoping review of risk factors of and interventions for adolescent repeat pregnancies: A public health perspective. Afr J Prm Health Care Fam Med. 2018;10(1), a1685. https://doi.org/10.4102/phcfm.v10i1.1685, for more information.

COCP, combined oral contraceptive pill; DMPA, depot medroxyprogesterone acetate; IPI, immediate postpartum implant; WCJF, Women's Centre of Jamaica Foundation; LARC, long acting reversible contraception; OR, Odds ratio; CAMI, computer assisted motivational intervention.

by Black et al. ${ }^{41}$ The mentorship was based on a 'big sister approach' and delivered over 19 home-based lessons. At 2 years postpartum, the adolescent mothers in the intervention group had a lower repeat pregnancy rate at $11 \%$ versus $24 \%$ in the control group. As with previous studies that have been discussed, the loss of participants at follow-up was significant because $18 \%$ of the mothers did not complete the 24 -month evaluation.
Barnet et al. ${ }^{42}$ conducted a randomised trial in Baltimore, MD, USA, to evaluate the effectiveness of MI through a computerassisted motivational intervention (CAMI) to prevent adolescent repeat pregnancies. Motivational Interviewing is a counselling approach that was used to help adolescent mothers find the motivation to facilitate positive behaviour change. ${ }^{42}$ The study recruited and trained counsellors on the computer-assisted MI. These counsellors provided motivation 
on use of contraception and condoms. The CAMI + group received education on infant development and care, feeding and nutrition, sexual and reproductive health, educational attainment and goal setting via biweekly home visits over a 24-month period. The CAMI-only group were visited at home on a quarterly basis. The CAMI and home visiting reduced the risk of rapid repeat adolescent pregnancies in the CAMI + group. In this respect, MI as an intervention can assist in reducing adolescent repeat pregnancies through behavioural change. $^{42}$

According to Lewis et al., ${ }^{22}$ contraception plays a vital role in the repeat adolescent pregnancy phenomenon. The frequency of research studies on contraceptive implants and repeat pregnancy rates in adolescents has continued to increase. ${ }^{4,22,26,43,44}$ Some of the findings that were most compelling arose from a study by Tocce et al., ${ }^{3}$ which revealed that only $2.6 \%$ of adolescent mothers $(n=4 / 153$; relative risk $=5.5$; $95 \%$; CI: 1.9 - 12.7) with immediate postpartum etonogestrel implant insertion experienced a repeat pregnancy at 12 months versus $18.6 \%(38 / 204)$ of the control participants. A retrospective study in the USA in the Medstar Washington Hospital by Damle et al. ${ }^{43}$ found reduced repeat pregnancy rates at 24 months amongst adolescent mothers who had initiated a long-acting reversible contraceptive within 8 weeks of delivery. A recent study by Cohen et al. ${ }^{44}$ also revealed that the repeat pregnancy rate is lower amongst adolescent mothers who initiate postpartum long-acting reversible contraceptives (LARC). In this regard, contraceptive implants could be an important intervention for adolescent repeat pregnancy.

\section{Discussion}

Adolescent repeat pregnancy has been studied extensively in other countries but in the African continent, studies on this phenomenon are scarce. With regard to the risk factors for adolescent repeat pregnancy, the ecological framework best explains this phenomenon. The results obtained by Mphatswe et al. ${ }^{8}$ on the prevalence and the risk factors on adolescent repeat pregnancy in KwaZulu-Natal, South Africa, were similar to that of other published studies around the globe. The scoping review of the literature demonstrates that interventions on secondary pregnancy prevention have positive outcomes for adolescents. These comprehensive interventions offered a wide range of medical services, education and psychosocial services which targeted repeat pregnancy, school enrolment and contraceptive uptake. Furthermore, the literature indicates that the ecological framework provides guidance on strategies to prevent adolescent repeat pregnancy.

The vast majority of interventions in this scoping review recruited participants from clinics, hospitals and community centres. In this regard, adolescent mothers not seeking health care would have been excluded. The findings of this scoping review illustrate the need for adolescent repeat pregnancy interventions to shift from individuals to the wider social and community context that influences adolescent sexual and reproductive health.
The FGC intervention by Solomon and Leifeld ${ }^{25}$ sought to change adolescent behaviour with emphasis on socioecological factors. The theoretical approaches used in the design of the FCG included the Ecological Model and the Family Support Model. The macroscopic ecological factors included social support, parenting skills and life stresses, whilst microscopic factors included home stimulation and child's temperament. Activities within the Ecological and Family Support Models included social and recreational, grandmother support groups, parenting classes, transportation services and developmental day camps. ${ }^{24}$

Interventions by Tocce et al., ${ }^{4}$ Lewis et al. ${ }^{22}$ and Steven-Simons et al. ${ }^{26}$ drew attention to the use of contraception in adolescents. In interpreting the results, it is noteworthy that contraception as an intervention plays a vital role in the adolescent repeat pregnancy phenomenon. In this regard, healthcare providers need to support adolescents in the access and use of contraceptives. The reported levels of contraception uptake and use are low amongst both married and unmarried adolescents. ${ }^{45,46}$ This implies that, though most married adolescents do not want a pregnancy, their contraceptive use is lower than that of sexually active unmarried adolescents. ${ }^{45}$

In a nutshell, there is an unmet need for contraception amongst adolescents in general. For example, a study in Nigeria by Ahanonu ${ }^{47}$ found that health care providers did not approve of adolescent premarital sex and that they, therefore, felt that prescribing contraceptives to adolescents was promoting promiscuity. Other factors that influence contraception use include: (1) sexual experiences, (2) psychosocial development, (3) gender issues, (4) previous health care experiences, (5) access to health care services, (6) access to information, (7) health and education structures and (8) social and cultural norms. ${ }^{46}$ In the South African context, Ehlers' ${ }^{48}$ explorative descriptive survey study found that only $48 \%$ of 250 adolescent mothers surveyed had used contraception.

A 'single one-size-fits-all' intervention for adolescent repeat pregnancy prevention is unlikely as different strategies were employed by the intervention programmes in this scoping review. In short, health care services need to be tailored to the needs of pregnant and parenting adolescents. Interventions can be implemented at various sites, including clinics, schools and community centres.

\section{Study limitations}

For practical reasons, only articles written in English were considered for this scoping review. The authors acknowledge that important published research may have been omitted using the method outlined in the search methodology. Rather, the review was designed to further illuminate the phenomenon of adolescent repeat pregnancy and to provide an understanding of what is known about the risk factors of and the interventions for adolescent repeat pregnancy. 


\section{Conclusion and recommendations}

Health services, health care workers and health information are essential building blocks of the public health system. According to the World Health Organization (WHO), ${ }^{49}$ the '...strengthening of health systems is everybody's business'. In this regard, the improvement of health care services for adolescent mothers is indeed everybody's business. Based on this review, it can be concluded that health care providers play an important role in the prevention of adolescent repeat pregnancies as it was shown that, across various studies, adolescent mothers who received medical, psychosocial, educational and family planning support experienced lower rates of repeat pregnancies.

To address the shortage of literature on adolescent repeat pregnancy in South Africa, future research needs to focus on this phenomenon and the strengthening of comprehensive health care services for adolescent mothers. Recommended for inclusion in future interventions, the Pinzon and Jones ${ }^{50}$ paediatric policy statement for the care of adolescent parents and their children highlights the following points: (1) continuity of care (creation of a medical home model), (2) provision of a multidisciplinary approach to care (nursing, social services, nutritional care, developmental screening services), (3) breastfeeding support, (4) contraception, (5) youth development, (6) promoting academic achievement, (7) promoting a healthy lifestyle, (8) addressing mental health issues, (9) parenting skills, (10) development of support groups and (11) active involvement of adolescent fathers. Adolescent repeat pregnancy is a huge burden on the adolescent mother, her family, her community and her country of residence. ${ }^{51}$ According to Morris and Rushwan, ${ }^{46}$ health care workers need to 'move away from being part of the problem to being part of the solution' (p. S41).

\section{Acknowledgements}

We would like to express our gratitude to Prof. Verusia Chetty and Dr Saul Cobbing for their comments that greatly improved the manuscript.

The research reported in this publication was supported by the Fogarty International Center (FIC), NIH Common Fund, Office of Strategic Coordination, Office of the Director (OD/ OSC/CF/NIH), Office of AIDS Research, Office of the Director $(\mathrm{OAR} / \mathrm{NIH})$, National Institute of Mental Health (NIMH/NIH) of the National Institutes of Health under Award Number D43TW010131. The content is solely the responsibility of the authors and does not necessarily represent the official views of the National Institutes of Health.

\section{Competing interest}

The authors declare that they have no financial or personal relationships that may have inappropriately influenced them in writing this article.

\section{Authors' contributions}

D.G. searched the databases, reviewed the literature and wrote the article. S.N. and M.T. assisted in the design of the article and also reviewed and edited the article.

\section{References}

1. Cook MCS, Cameron ST. Social issues of teenage pregnancy. Obstet Gynaecol Reprod Med. 2015;25(9):243-248. https://doi.org/10.1016/j.ogrm.2015.06.001

2. Darroch J, Woog V, Bankole A, Ashford LS. Adding it up: Costs and benefits of meeting the contraceptive needs of adolescents. New York: Guttmacher Institute, WHO; 2016.

3. World Health Organization. Global health estimates 2015: Deaths by cause, age, sex, by country and by region, 2000-2015. Geneva: WHO; 2016

4. Tocce KM, Sheeder JL, Teal SB. Rapid repeat pregnancy in adolescents: Do immediate postpartum contraceptive implants make a difference? Am J Obste Gynaecol. 2012;206(481):e1-e7. https://doi.org/10.1016/j.ajog.2012.04.015

5. Maravilla JC, Betts KS, Abajobir AA, Cruz CC, Alati R. The role of community health workers in preventing adolescent repeat pregnancies. I Adolesc Health 2016;59(4):378-390. https://doi.org/10.1016/j.jadohealth.2016.05.011

6. Best Start Resource Centre. Subsequent teen pregnancies: Exploring the issues, impact and effectiveness of prevention strategies. [homepage on the Internet]. 2009 [cited 2016 Nov 22]. Available from: http://www. beststart.org/resources/.../ subsequent teen pregnancies

7. Whitaker R, Hendry M, Booth A, et al. Intervention Now To Eliminate Repeat Unintended Pregnancy in Teenagers (INTERUPT): A systematic review of intervention effectiveness and cost-effectiveness qualitative and realist synthesis of implementation factors and user engagement. Br Med J Open. 2014;4(4): e004733. https://doi.org/10.1136/bmjopen-2013-004733

8. Mphatswe W, Maise H, Sebitloane M. Prevalence of repeat pregnancies and associated factors among teenage mothers in KwaZulu Natal. Int J Gynecol Obstet. 2016;133:152-155. https://doi.org/10.1016/j.ijgo.2015.09.028

9. Barnet B, Liu J, DeVoe M, Alperovitz-Bichell K, Duggan AK. Home visiting for adolescent mothers: Effects on parenting, maternal life course, and primary care linkage. Ann Fam Med. 2007;5(3):224-232. https://doi.org/10.1370/afm.629

10. Boardman L, Allsworth J, Phipps M, Lapane K. Risk factors for unintended versus intended rapid repeat pregnancies among adolescents. J Adolesc Health. 2006; 36:597e1-8.

11. Dillon ME. Adolescent pregnancy in mental health. In: Dillon ME, Cherry AL, editors. International handbook of adolescent pregnancy: Medical, psychosocial and public health responses. New York: Springer, 2014; p. 79-102.

12. Conroy KN, Engelhart MHS, Martins $Y$, et al. The enigma of rapid repeat pregnancy: A qualitative study of teen mothers. J Pediatr Adolesc Gynecol. 2016:312-317. https://doi.org/10.1016/j.jpag.2015.12.003

13. The Schuyler Centre for Analysis and Advocacy. Teenage births: Outcomes for young parents and their children. [homepage on the Internet]. 2008 [cited 2016 Dec 15]. Available from: http://www.scanny.org/.../teen_pregnancy

14. Pfitzner MA, Hoff $C$, McElligott $K$. Predictors of Repeat pregnancy in a program for pregnant teens. J Pediatr Adolesc Gynecol. 2003;16:77-81. https://doi.org/ 10.1016/S1083-3188(03)00011-1

15. Macleod C. 'Adolescence', pregnancy and abortion: Constructing a threat of degeneration. London: Routledge, 2011; xi-168 p.

16. Seamark CJ, Lings P. Positive experiences of teenage motherhood: A qualitative study. Br J Gen Pract. 2004;54(508):813-818.

17. Smith GCS, Pell JP. Teenage pregnancy and risk of adverse perinatal outcomes associated with first and second births: Population-based cohort study. Br Med J. 2001;323:1-5. https://doi.org/10.1136/bmj.323.7311.476

18. Lawlor DA, M S. Too much too young? Teenage pregnancy is not a public health problem. Int J Epidemiol. 2002;31(3):552-553. https://doi.org/10.1093/ije/ problem.

19. Scally G. Too much too young? Teenage pregnancy is a public health, not a clinical problem. Int J Epidemiol. 2002;31(3):554-555. https://doi.org/10.1093/ije/ 31.3.554

20. Rich-Edwards J. Teenage pregnancy is not a public health crisis in the United States. It is time we made it one. Int J Epidemiol. 2002;31(3):555-556. https://doi. org/10.1093/ije/31.3.555

21. Cox JE, Burman MP, Woods ER, Famakinwa O, Harris SK. Evaluation of raising adolescent families' together program: A medical home for adolescent mothers and their children. Am J Pub Health. 2012;102(10):1879-1885. https://doi.org/10.2105/ AJPH.2012.300766

22. Lewis LN, Doherty DA, Hickey M, Skinner SR. Predictors of sexual intercourse and rapid repeat pregnancy among teenage mothers: An Australian prospective rapid repeat pregnancy among teenage mothers:
longitudinal study. Med J Aust. 2010;193(6):338-342.

23. Jacoby M, Gorenflo D, Black E, Wunderlich C, Eyler E. Rapid repeat pregnancy and experiences of interpersonal violence among low income individuals. Am J Prev Med. 1999;16(4):318-321. https://doi.org/10.1016/S0749-3797(99)00029-X

24. Raneri LG, Wiemann M. Social ecological predictors of repeat adolescent pregnancy. Perspect Sex Reprod Health. 2007;39(1):39-47. https://doi.org/ 10.1363/3903907

25. Solomon R, Leifeld CP. Effectiveness of a family support centre approach to adolescent mothers: Repeat pregnancy and school dropout. Fam Relat. 1998; 47(2):139-144. https://doi.org/10.2307/585617 
26. Steven-Simons C, Kelly S, Singer D. Preventing repeat adolescent pregnancies with early adoption of the contraceptive implant. Fam Plann Perspect. 1999:31(2):8893. https://doi.org/10.2307/2991646

27. Arksey H, O'Malley. Scoping studies: Towards a methodological framework. Int J Soc Res Methodol. 2005;8(1):19-32. https://doi.org/10.1080/1364557032000119616

28. Levac D, Colquhoun H, O'Brien KK. Scoping studies: Advancing the methodology Implement Sci. 2010;5:69. https://doi.org/10.1186/1748-5908-5-69

29. Davis K, Drey N, Gould D. A review of nursing literature. Int J Nurs Stud. 2009;46(10):1386-1400. https://doi.org/10.1016/j.ijnurstu.2009.02.010

30. Rowland S. Social predictors of repeat adolescent pregnancy and focused strategies. Best Pract Res Clin Obstet Gynecol. 2010;24(5):605-616. https://doi. org/10.1016/j.bpobgyn.2010.02.016

31. Rigsby DC, Macones GA, Driscoll DA. Risk factors for rapid repeat pregnancy among adolescent Mothers: A review of the literature. J Pediatr Adolesc Gynecol. 1998;11:115-126. https://doi.org/10.1016/S1083-3188(98)70130-5

32. Rosenguard $\mathrm{C}$. Confronting the intendedness of adolescent rapid repeat pregnancy J Adolesc Health. 2009;44:5-6. https://doi.org/10.1016/j.jadohealth.2008.10.132

33. Rabin JM, Seltzer $V$, Ventura S. A randomised trial of a health care program for first time adolescent mothers and their infants. Clin Paediatr. 1991:301-305.

34. O'Sullivan AL, Jacobsen BS. A randomised trial of a health care program for first time adolescent mothers. Nurs Res. 1992;41(4):210-215.

35. Drayton VL, Montgomery SB, Modeste NN, Frye-Anderson BA, McNeil P. The impact of the Women's Centre of Jamaica Foundation Programme for adolescent mothers on repeat pregnancies. West Indian Med J. 2000;49(4):316-326.

36. Ford K, Weglicki L, Kershaw T, Schram C, Hoyer PJ, Jacobson MI. Effects of a prenatal care intervention on adolescent mothers on birth weight, repeat
pregnancy, and educational outcomes at one year postpartum. J Perinat Educ. 2002;11(1):35-38. https://doi.org/10.1624/105812402X88588

37. Seitz V, Apfel NH. Adolescent mothers and repeated childbearing: Effects of a school-based intervention program. Am J Orthopyschiatry. 1993;63(4):572-581. https://doi.org/10.1037/h0079483

38. Key JD, Gebregziabher MG, Marsh LD, O'Rourke KM. Effectiveness of an intensive, school-based intervention for teen mothers. J Adolesc Health. 2008;42:394-400. https://doi.org/10.1016/j.jadohealth.2007.09.027

39. Corocan J, Pillai VK. Effectiveness of secondary prevention programs: A metanalysis. Res Soc Work Pract. 2007;17(5):5-17. https://doi.org/10.1177/1049731506291583
40. Olds DL, Robinson JA, O'Brien R, et al. Home visiting by paraprofessionals and by nurses: A randomised control trial. Am Acad Paediatr. 2002;110(3):486-496.

41. Black MM, Bentley ME, Papas MA, et al. Delayed second births among adolescent t mothers: A randomised, controlled trial of a home-based mentoring programme. Paediatrics. 2006;118:1087-1099. https://doi.org/10.1542/peds.2005-2318

42. Barnet B, Luiu J, DeVoe M, Duggan AK, Gold MA, Pecukonis E. Motivationa intervention to reduce rapid subsequent births to adolescent mothers: A community based randomised trial. Ann Fam Med. 2009;7(5):436-445. https:// doi.org/10.1370/afm.1014

43. Damle LF, Gohari AC, McEvoy AK, Desale SY, Gomez-Lobo V. Early initiation of postpartum contraception: Does it decrease rapid repeat pregnancy in adolescents? J Pediatr Adolesc Gynecol. 2015;28:57-62. https://doi.org/10.1016/j. jpag.2014.04.005

44. Cohen R, Sheeder J, Arango N, Teal SB, Tocce K. Twelve-month contraceptive continuation and repeat pregnancy among young mothers choosing postdelivery contraceptive implants or postplacental intrauterine devices. Contraception. 2015;93:178-183. https://doi.org/10.1016/j.contraception.2015. 10.001

45. Rivera R. Contraception in adolescence [homepage on the Internet]. Geneva: World Health Organization; 2004 [cited 2016 Nov 22]. Available from: http:// www.who.int/iris/handle/10665/42901

46. Morris JL, Rushwan H. Adolescent sexual and reproductive health: Global challenges. Int J Gynecol Obstetr. 2015;131(1):S40-S42. https://doi.org/10.1016/j. ijgo.2015.02.006

47. Ahanonu EL. Attitudes of healthcare providers towards providing contraceptives for unmarried adolescents in Ibadan, Nigeria. J Fam Reprod Health. 2013;8(1): 33-40.

48. Ehlers VJ. Adolescent mothers' utilisation of contraceptive services in South Africa. Int Nurs Rev. 2003;50:229-241. https://doi.org/10.1046/j.1466-7657.2003. 00187.x

49. World Health Organization. Strengthening health systems to improve health outcomes [homepage on the Internet]. Geneva: Switzerland; 2007 [cited 2016 Dec 15]. Available from: www.who.int/healthsystems/.../index5.ht

50. Pinzon JL, Jones VF. Care of adolescent parents and their children. Pediatrics. 2012;130(6):1743-1756. https://doi.org/10.1542/peds.2012-2879

51. Porter LS, Holness NA. Breaking the repeat pregnancy cycle. Nurs Women Health 2011;15(5):368-381. https://doi.org/10.1111/j.1751-486X.2011.01661.x 